\title{
TURFEIRAS DA SERRA DO ESPINHAÇO MERIDIONAL - MG. II - INFLUÊNCIA DA DRENAGEM NA COMPOSIÇÃO ELEMENTAR E SUBSTÂNCIAS HÚMICAS ${ }^{(1)}$
}

\author{
Alexandre Christófaro Silva(2), Ingrid Horák ${ }^{(3)}$, Pablo Vidal-Torrado(4), \\ Antonio Martinez Cortizas ${ }^{(5)}$, Jose Rodrigues Racedo ${ }^{(5)}$ \& José Ricardo \\ da Rocha Campos ${ }^{(6)}$
}

\begin{abstract}
RESUMO
As turfeiras são Organossolos que resultam de condições ecológicas ideais ao acúmulo de material orgânico, controladas pelos sistemas geomorfológicos e processos geológicos e climáticos globais. Sua constituição física, química e biológica é pouco conhecida. No presente trabalho foi realizado um estudo sobre as turfeiras da Serra do Espinhaço Meridional (SdEM) - MG, por meio da descrição e coleta de amostras em três perfis situados a $1.250 \mathrm{~m}(\mathrm{P} 1), 1.350 \mathrm{~m}$ (P4) e $1.800 \mathrm{~m}$ (P2) de altitude. Os três perfis foram caracterizados morfologicamente e, nas amostras coletadas, foram realizadas análises químicas e fracionamento da matéria orgânica em ácidos húmicos, ácidos fúlvicos e humina. A matéria orgânica dos perfis de Turfeiras da SdEM apresentou marcantes diferenças entre si em relação à sua composição química e ao teor das substâncias húmicas e à composição química dos ácidos húmicos. A variação das condições de drenagem foi preponderante para a diferenciação qualitativa e quantitativa da matéria orgânica. A turfeira P1, com moderadas condições de drenagem, apresentou matéria orgânica com maiores relações $\mathrm{C} / \mathrm{N}$ e $\mathrm{O} / \mathrm{C}$, predomínio de ácidos fúlvicos entre as substâncias húmicas e ácidos húmicos e elevada relação $\mathrm{C} / \mathrm{N}$. Nas turfeiras P2 e P4, com muito más condições de drenagem, as relações $\mathrm{C} / \mathrm{N}$ e $\mathrm{O} / \mathrm{C}$ da matéria orgânica foram mais baixas, a humina predominou amplamente entre as substâncias húmicas e os ácidos húmicos apresentaram a mais baixa relação $\mathrm{C} / \mathrm{N}$.
\end{abstract}

Termos de indexação: Organossolos, matéria orgânica do solo, ácidos fúlvicos, ácidos húmicos, humina.

\footnotetext{
${ }^{(1)}$ Recebido para publicação em novembro de 2008 e aprovado em maio de 2009.

(2) Professor da Faculdade de Ciências Agrárias, Universidade Federal dos Vales do Jequitinhonha e Mucuri - UFVJM. Caixa Postal 38, CEP 39100-000 Diamantina (MG). E-mail: alexandre.christo@ufvjm.edu.br

(3) Bolsista de Iniciação Científica da FAPEMIG, UFVJM. E-mail: ihorak@esalq.usp.br

(4) Professor do Departamento de Solos e Nutrição de Plantas, Escola Superior de Agricultura "Luiz de Queiroz" - ESALQ/USP. Caixa Postal 9, Av. Pádua Dias 11, CEP 13418-900 Piracicaba (SP). E-mail: pablo@carpa.ciagri.usp.br

${ }^{(5)}$ Departamento de Edafoloxia, Facultad de Bioloxia, Universidad de Santiago de Compostela. CP 15706, Santiago de Compostela, Espanha. E-mail: edanton@usc.es

${ }^{(6)}$ Discente do Programa de Mestrado em Produção Vegetal, UFVJM. E-mail: agrocel_1@yahoo.com.br
} 


\title{
SUMMARY: PEAT BOGS IN THE SERRA DO ESPINHAÇO MERIDIONAL - MINAS GERAIS, BRAZIL. II - INFLUENCE OF DRAINAGE ON ELEMENTAL HUMUS COMPOSITION AND SUBSTANCES
}

\begin{abstract}
Peat bogs are Organosols formed under ideal ecological conditions in terms of the accumulation of organic material, controlled by geomorphological and geological processes and climate. The physical, chemistry and biological constitution of peat bogs is largely unknown. In this study the peat bogs of the Southern Serra do Espinhaço (Minas Gerais, Brazil) were described and sampled from three profiles at 1,250 m (P1), 1,350 m (P4) and 1,800 m (P2) above sea level. The three profiles were characterized morphologically, the collected samples were chemically analyzed and the organic matter was fractioned in humin, fulvic and humic acids. The organic matter of the peat bog profiles differed strikingly in chemical composition and contents of humic substances and in the chemical composition of humic acids. The variations in drainage conditions were mostly responsible for the qualitative and quantitative differentiation of organic matter. In peat bog $P 1$, with moderate drainage, the $C / N$ and $O / C$ ratios of the organic matter were higher, fulvic acid predominant among the humic substances and humic acids had a higher $C / N$ ratio. In the peat bog $P 2$ and $P 4$, with very poor drainage, $\mathrm{C} / \mathrm{N}$ and $\mathrm{O} / \mathrm{C}$ ratios were lower in the organic matter, humin largely predominant among humic substances and $C / N$ ratios in humic acids were lowest.
\end{abstract}

Index terms: Organosols, soil organic matter, fulvic acids, humic acids, humin.

\section{INTRODUÇÃO}

A Serra do Espinhaço Meridional (SdEM) é caracterizada por apresentar áreas dissecadas entremeadas a superfícies de aplainamento, em que, nas depressões, ocorrem vários tipos de turfeiras, as quais são grandes reservatórios de carbono. Essas turfeiras estão colonizadas por vegetação de campo rupestre e são relacionadas com a biodiversidade, com o volume e com a qualidade das águas de uma vasta área do Brasil, representada pelas bacias dos rios Jequitinhonha, Doce e São Francisco.

Em 2005, a SdEM foi alçada pela Unesco à condição de "Reserva da Biosfera Terrestre" (Silva et al., 2005), o que ressalta a importância de preservação de seus ecossistemas turfosos, cujos solos foram classificados como Organossolo Háplico Sáprico térrico, Organossolo Háplico Fíbrico típico e Organossolo Háplico Hêmico típico (Silva et al., 2009), de acordo com o Sistema Brasileiro de Classificação de Solos (Embrapa, 2006).

A composição química das turfeiras é influenciada diretamente pela fração mineral, pela natureza do material orgânico, pelo grau de decomposição da matéria orgânica, pela drenagem e pela composição química da água de formação, o que contribui para que ocorra ampla variação na composição entre e dentro dos seus perfis (Andriesse, 1988; Galvão \& Vahl, 1996).

A maior parte das turfeiras da SdEM possui mais de $50 \%$ de matéria orgânica (Silva et al., 2005), constituída, em sua maior parte, por substâncias húmicas mais estáveis, caracterizadas por maior recalcitrância a degradação e maior reatividade (Horak et al., 2007).
De acordo com Senesi \& Loffredo (1999), substâncias húmicas correspondem a misturas de moléculas heterogêneas, amorfas, coloidais, formadas de reações de síntese, durante o decaimento e a transformação da matéria orgânica pela atividade microbiana. Para Camargo et al. (1999), essas substâncias são formadas pela humificação de resíduos orgânicos pelos microrganismos no solo e pela polimerização dos compostos orgânicos em macromoléculas resistentes à degradação biológica.

Segundo Stevenson (1994), as substâncias húmicas (humina, ácidos fúlvicos e ácidos húmicos) são consideradas a parte final da evolução da matéria orgânica do solo e representam cerca de 70 \% do C no solo; são diferenciadas, principalmente, por meio dos grupos funcionais (fenólicos, carboxílicos, entre outros) e do grau de polimerização. Os ácidos húmicos são insolúveis em meio ácido e solúveis em meio básico e possuem estrutura maior $\left(8 \times 10^{-10} \mathrm{~m}\right.$, e complexa, quando comparados com os ácidos fúlvicos, os quais são completamente hidrossolúveis, com tamanho pequeno $\left(2 \times 10^{-10} \mathrm{~m}\right)$, maiores grupamentos carboxílicos e de oxigênio e menor concentração de C, favorecendo sua percolação no solo. No caso da humina, esta é insolúvel em meio ácido e básico e tem maior grau de polimerização que os ácidos fúlvicos e húmicos (Primavesi, 1990; Schnitzer et al., 1991).

Valladares et al. (2008), trabalhando com Organossolos mésicos e háplicos (Embrapa, 1999) de diferentes pedoambientes das regiões Sul, Sudeste e Centro-Oeste do Brasil, encontraram teores de ácidos fúlvicos variando entre 13 e $38 \mathrm{~g} \mathrm{~kg}^{-1}$ (média de $17,8 \mathrm{~g} \mathrm{~kg}^{-1}$ ); de ácidos húmicos, entre 27 e $129 \mathrm{~g} \mathrm{~kg}^{-1}$ 
(média de 68,8 $\mathrm{g} \mathrm{kg}^{-1}$ ); e de humina, entre $10 \mathrm{e}$ $139 \mathrm{~g} \mathrm{~kg}^{-1}$ (média de $64 \mathrm{~g} \mathrm{~kg}^{-1}$ ).

A matéria orgânica das turfeiras da SdEM é pouco conhecida e sua caracterização pode acelerar o entendimento da dinâmica e reações da matéria orgânica em regiões tropicais, uma vez que elas apresentam matéria orgânica de diferentes idades e estádios de decomposição.

No presente trabalho foi testada a hipótese de que o acúmulo e grau de decomposição da matéria orgânica se relacionam com as condições de drenagem e com os teores e a composição elementar das frações húmicas isoladas desses solos.

\section{MATERIAL E MÉTODOS}

\section{Caracterização da área estudada}

No Espinhaço Meridional, superfícies de aplainamento escalonadas estão separadas por áreas com alto grau de dissecação, onde o relevo é montanhoso e escarpado e são muito frequentes os afloramentos de rochas metareníticas do Supergrupo Espinhaço. Nas superfícies de aplainamento, ocorrem associações de Neossolos Quartzarênicos Hidromórficos com Organossolos, colonizados principalmente por espécies do campo rupestre, como as sempre-vivas. O clima é Cwb, de acordo com a classificação de Köppen, ou seja, mesotérmico. A temperatura média anual é de $18,7^{\circ} \mathrm{C}$, e as chuvas ocorrem principalmente entre outubro e março, enquanto os meses de junho a agosto são normalmente secos (Silva et al., 2005).

\section{Amostragem}

A coleta das amostras de solo foi realizada em três perfis de turfeiras da SdEM: P1 (coordenadas UTM 649691 E e 7994039 N; 1.250 m de altitude); P2 (coordenadas UTM 675923 E e $7965062 \mathrm{~N} ; 1.800 \mathrm{~m}$ de altitude); P4 (coordenadas UTM 639167 E e 7979340 $\mathrm{N} ; 1.350 \mathrm{~m}$ de altitude).

Em P1 foram coletadas amostras nas seguintes profundidades, de acordo com a morfologia das camadas: $6-66,80-116,118-122,124-132,140-150$, 156-166 e 170-174 cm. Os perfis P2 e P4 apresentaram, respectivamente, 50 e $90 \mathrm{~cm}$ de profundidade, e em ambos a amostragem foi feita a cada $10 \mathrm{~cm}$, em razão da homogeneidade das camadas dentro desses perfis.

\section{Determinações analíticas}

No campo, foi realizado o teste para determinação do estádio de decomposição das camadas das turfeiras, utilizando a escala de decomposição de von Post (Stanek \& Silc, 1977), descrita em Embrapa (2006). O método consiste na compressão de uma amostra de turfeira entre os dedos e avaliação da presença e coloração da água extraída pela compressão.
Para realização das análises em laboratórios, as amostras foram secas ao ar, destorroadas e passadas em peneiras de malha de $2,0 \mathrm{~mm}$, obtendo-se assim a terra fina seca ao ar (TFSA).

Quanto à quantificação dos teores de carbono orgânico (Corg), a TFSA foi moída em gral de porcelana e tamisada na peneira de $0,053 \mathrm{~mm}$ e, posteriormente, colocada em estufa a $105 / 110^{\circ} \mathrm{C}$ por $24 \mathrm{~h}$ para secagem completa. Para determinação do Corg foram utilizados três métodos: um deles baseia-se na oxidação da matéria orgânica por soluções de agentes oxidantes, como o dicromato em meio ácido a frio (Walkley \& Black, 1934), e os outros na combustão a seco, respectivamente em Analisador de Elementos LECO CHN 1000 e em Analisador de Elementos Flashea 1112 Series NCS (Nelson \& Sommers, 1996), utilizando os seguintes materiais de referência: Acetanilide SRM lote n.141d e Cystine SRM lote n. 143d. Na determinação da matéria orgânica utilizou-se a combustão em forno mufla $600{ }^{\circ} \mathrm{C} / 6$ horas (Embrapa, 2006).

A densidade do solo (DS), a densidade da matéria orgânica (Dmo) e o material mineral (MM) foram determinados de acordo com o método de caracterização de Organossolos (Embrapa, 2006). Os teores de areia, silte e argila foram determinados pelo método da pipeta (Embrapa, 1997), após a queima total da matéria orgânica das amostras com $\mathrm{H}_{2} \mathrm{O}_{2}$, para obtenção da fração mineral (FM).

Para a determinação de C, H, N, O e S totais, a TFSA das amostras coletadas a cada $2 \mathrm{~cm}$ de profundidade foi moída no gral de porcelana e tamisada na peneira de $0,053 \mathrm{~mm}$, sendo posteriormente colocadas em estufa a $105 / 110^{\circ} \mathrm{C}$ por $24 \mathrm{~h}$ para secagem completa. Essas análises foram realizadas em analisador elementar LECO CHN 1000 (Nelson \& Sommers, 1996), usando como materiais de referência Elemental Micronalysis B2115 e B2152, LECO 502-092, 502-308 e 502-309.

$\mathrm{O}$ fracionamento da matéria orgânica humificada das turfeiras em ácidos fúlvicos (AF), ácidos húmicos $(\mathrm{AH})$ e humina $(\mathrm{H})$ foi realizado na TFSA, de acordo com método da International Society of Humic Substances (Swift, 1996). Resumidamente, $20 \mathrm{~g}$ de solo seco em estufa a $105 / 110^{\circ} \mathrm{C}$ por $24 \mathrm{~h}$ foram agitados durante $12 \mathrm{~h}$ em atmosfera inerte $\left(\mathrm{N}_{2}\right)$ em $200 \mathrm{~mL}$ de solução $\mathrm{NaOH} 0,1 \mathrm{~mol} \mathrm{~L}^{-1}$. Os extratos foram centrifugados a $14.250 \mathrm{~g}$ por $30 \mathrm{~min}$, separados dos resíduos e os sobrenadantes centrifugados novamente, coletados e acidificados a pH 1-2 com $\mathrm{HCl}$ $61 \mathrm{~mol} \mathrm{~L}^{-1}$ e decantados por $12 \mathrm{~h}$. Os AH precipitaram e foram separados dos AF por sifonamento, e estes foram centrifugados a $14.250 \mathrm{~g}$ durante $30 \mathrm{~min}$. Os AF extraídos foram liofilizados e posteriormente secos em estufa a $40{ }^{\circ} \mathrm{C}$ e pesados. Nos AF liofilizados o conteúdo de cinzas foi determinado queimando-se $20 \mathrm{mg}$ de $\mathrm{AF}$ a $600{ }^{\circ} \mathrm{C}$ durante quatro horas.

Após a separação dos AF, os AH foram dissolvidos em solução $\mathrm{KOH} 0,1 \mathrm{~mol} \mathrm{~L}^{-1}+\mathrm{KCl}$, para atingir a concentração de $0,3 \mathrm{~mol} \mathrm{~L}^{-1}$ de $\mathrm{K}^{+}$, e centrifugados novamente. Os $\mathrm{AH}$ foram ressuspensos em uma 
solução de $\mathrm{HCl} 0,1 \mathrm{~mol} \mathrm{~L}^{-1}+\mathrm{HF}$ 0,3 $\mathrm{mol} \mathrm{L}^{-1}$, agitados durante $12 \mathrm{~h}$, centrifugados, dialisados com água ultrapura em membrana de 6.000-8.000 dáltons até a condutividade elétrica da solução ser menor que $10 \mu \mathrm{S} \mathrm{cm}^{-1}$ e liofilizados. Posteriormente, foram secos em estufa a $40^{\circ} \mathrm{C}$ e pesados. Nos AH liofilizados, o conteúdo de cinzas foi determinado queimando-se $20 \mathrm{mg}$ de $\mathrm{AH}$ a $600^{\circ} \mathrm{C}$ durante quatro horas.

$\mathrm{O}$ material que permaneceu precipitado após a separação dos $\mathrm{AH}$ corresponde a humina $(\mathrm{H})$, a qual foi seca em estufa a $40^{\circ} \mathrm{C}$ e pesada. Seu conteúdo de cinzas foi determinado queimando-se $20 \mathrm{mg}$ de humina a $600{ }^{\circ} \mathrm{C}$ durante quatro horas.

Os teores de $\mathrm{C}, \mathrm{N}$ e $\mathrm{S}$ das substâncias húmicas (AF, $\mathrm{AH}$ e H) foram quantificados por combustão a seco em Analisador de Elementos Flashea 1112 Series NCS (Nelson \& Sommers, 1996), utilizando os seguintes materiais de referência: Acetanilide SRM lote n.141d e Cystine SRM lote n. 143d.

\section{Análises estatísticas}

Determinou-se o modelo de equação de regressão que melhor explica o comportamento de uma variável- resposta em função de uma variável preditora e estimou-se o coeficiente de correlação de Pearson (r) entre os valores da variável preditora e os valores esperados para a variável-resposta. A significância de $r$ foi estimada pelo teste t de Student a $5 \%(p<0,05)$ e a $1 \%(p<0,01)$. Procedeu-se à análise de variância (classificação hierárquica) para verificar diferenças estatisticamente significativas entre os perfis estudados, para todas as variáveis quantitativas. $\mathrm{Na}$ determinação do contraste entre médias utilizou-se o teste de Scheffé a $5 \%(p<0,05)$.

\section{RESULTADOS E DISCUSSÃO}

\section{Caracterização da matéria orgânica}

Todos os métodos de determinação do carbono orgânico do solo correlacionaram-se linear e positivamente e não houve diferença estatisticamente significativa entre eles (Quadro 1). O maior valor do coeficiente de correlação $\left(\mathrm{n}=21, \mathrm{r}=0,9890^{* *}\right.$, p < 0,001) foi obtido entre os Analisadores Elementares LECO CHN 1000 e Flashea 1112 NCS.

Quadro 1. Teores de carbono orgânico pelos métodos do Analisador Elementar, Walkley \& Black e teores de matéria orgânica obtidos pelo método da mufla $600^{\circ} \mathrm{C} / 6$ horas das amostras das turfeiras da Serra do Espinhaço Meridional

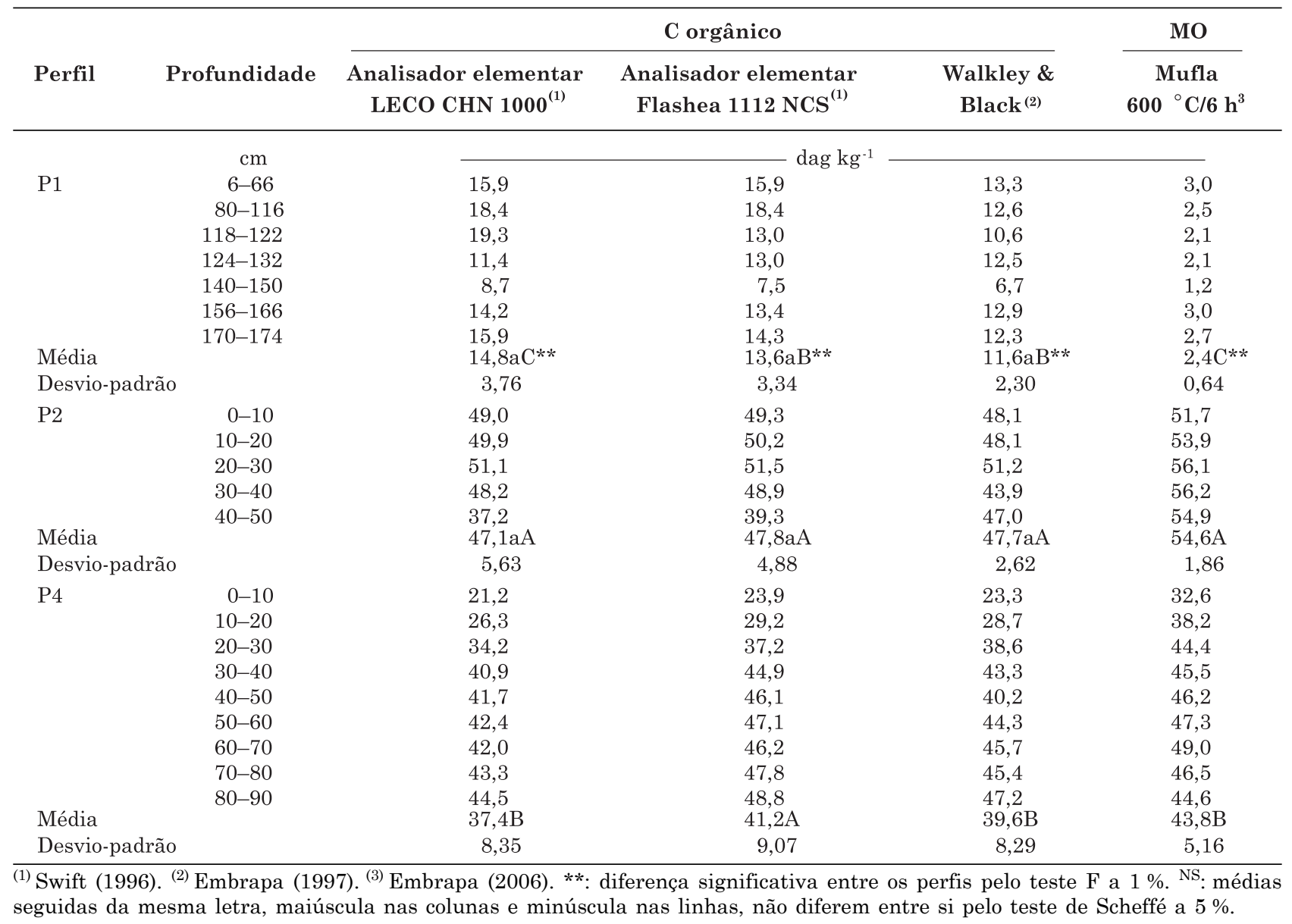


Os teores médios de matéria orgânica obtidos pelo método da mufla (Embrapa, 2006) diferem entre os perfis ( $\mathrm{p}<0,01$ pelo teste $\mathrm{F}$ e $\mathrm{p}<0,05$ pelo teste de Scheffé) (Quadro 1). Esses teores, quando divididos pelo fator 1,724 (utilizado para transformar teor de matéria orgânica em teor de Corg, considerando que a matéria orgânica possui $58 \%$ de Corg), são muito inferiores aos teores médios de Corg obtidos pelos outros métodos em todas as camadas de todos os perfis. Como a matéria orgânica não é formada somente por Corg, pode-se inferir que o método da mufla subestima o teor de matéria orgânica das amostras. Essa subestimação pode estar relacionada, em $\mathrm{P} 1$, aos teores mais baixos de matéria orgânica (MO) e mais elevados valores da fração mineral (FM), onde predomina a fração areia, à baixa densidade da matéria orgânica (Dmo) e à elevada densidade do solo (DS) neste perfil (Quadro 2). Nessas condições, pode-se inferir que a queima de matéria orgânica em mufla não altera significativamente a massa da amostra. Outro fator que pode contribuir para a subestimação dos teores de matéria orgânica em todos os perfis estudados é a formação de complexos organominerais, que a protegem da queima (Breemen \& Buurman, 2002). Novos trabalhos devem ser realizados para testar a eficiência do método da mufla a $600^{\circ} \mathrm{C}$ por $6 \mathrm{~h}$ (Embrapa, 2006) na determinação do teor de matéria orgânica de amostras de Organossolos.

Os teores de Corg correlacionaram-se positiva e linearmente e com o teor de $\mathrm{N}$ das amostras $(\mathrm{n}=21$, $\left.\mathrm{r}=0,7780^{* *}, \mathrm{p}<0,01\right)$. Os perfis $\mathrm{P} 2$ e P4 apresentaram teores mais elevados de $\mathrm{N}$ em relação a $\mathrm{P} 1(\mathrm{p}<0,01$ pelo teste $\mathrm{Fe} \mathrm{p}<0,05$ pelo teste de Scheffé) (Quadro 3). A disponibilidade de $\mathrm{N}$ é influenciada pela temperatura, pelo teor de água do solo, pela aeração e pela acidez (Andriesse, 1988), assim como as pequenas variações da relação C/N (Blombäck et al., 2003). Em P2 e P4, saturados com água o ano todo, onde a temperatura e a aeração são baixas e a acidez é elevada, o teor de $\mathrm{N}$ diminuiu e a relação $\mathrm{C} / \mathrm{N}$ aumentou com a profundidade (Quadro 3).

Quadro 2. Drenagem, densidade do solo (DS), densidade da matéria orgânica (Dmo), carbono orgânico (Corg), fração mineral (FM), relação FM/MO e teores de areia, silte e argila em perfis de turfeiras da Serra do Espinhaço Meridional

\begin{tabular}{|c|c|c|c|c|c|c|c|c|c|c|}
\hline Perfil & Drenagem & Profundidade & $\mathbf{D S}^{(1)}$ & $\operatorname{Dmo}^{(1)}$ & C org ${ }^{(2)}$ & $F M^{(1)}$ & FM/C & Areia & Silte & Argila \\
\hline & & $\mathrm{cm}$ & $-\mathrm{kg} \mathrm{dn}$ & $n^{-3}-$ & — dag $\mathrm{k}$ & $g^{-1}-$ & & $\longrightarrow$ & $\%$ do MM & I \\
\hline \multirow[t]{7}{*}{$\mathrm{P} 1$} & & 6-66 & 1,29 & 0,07 & 15,9 & 72,6 & 4,57 & 94 & 5 & 1 \\
\hline & & $80-116$ & 1,34 & 0,06 & 18,4 & 68,3 & 3,71 & 97 & 3 & 0 \\
\hline & & $118-122$ & 1,38 & 0,05 & 13,0 & 77,6 & 5,96 & 21 & 78 & 0 \\
\hline & Moderada & $124-132$ & 1,31 & 0,05 & 13,0 & 77,6 & 5,96 & 76 & 3 & 21 \\
\hline & & $140-150$ & 1,38 & 0,03 & 7,5 & 87,0 & 11,60 & 86 & 13 & 1 \\
\hline & & $156-166$ & 1,42 & 0,07 & 13,4 & 76,9 & 5,74 & 91 & 9 & 0 \\
\hline & & $170-174$ & 1,35 & 0,06 & 14,3 & 75,4 & 5,27 & 25 & 74 & 0 \\
\hline Média & & & $1,35 \mathrm{~A}^{* *}$ & $0,06 \mathrm{~B}^{* *}$ & $13,6 \mathrm{~B} * *$ & $76,5 \mathrm{~A}^{* *}$ & $5,62 \mathrm{~A}^{* *}$ & $71 \mathrm{~A}^{\mathrm{ns}}$ & $26 \mathrm{~A}^{\mathrm{ns}}$ & $3 \mathrm{~A}^{\mathrm{ns}}$ \\
\hline Desvio-padrão & & & 0,04 & 0,01 & 3,34 & 5,72 & 2,55 & 32,82 & 34,07 & 7,83 \\
\hline \multirow[t]{5}{*}{$\mathrm{P} 2$} & & $0-10$ & 0,37 & 0,24 & 49,3 & 15,0 & 0,30 & 73 & 25 & 2 \\
\hline & & $10-20$ & 0,41 & 0,31 & 50,2 & 13,4 & 0,27 & 0 & 95 & 5 \\
\hline & Muito má & $20-30$ & 0,31 & 0,30 & 51,5 & 11,2 & 0,22 & 13 & 83 & 4 \\
\hline & & $30-40$ & 0,28 & 0,27 & 48,9 & 15,6 & 0,32 & 25 & 71 & 4 \\
\hline & & $40-50$ & 0,37 & 0,35 & 39,3 & 32,2 & 0,82 & 74 & 21 & 5 \\
\hline Média & & & $0,35 \mathrm{~B}$ & $0,29 \mathrm{~A}$ & $47,8 \mathrm{~A}$ & $17,6 \mathrm{~B}$ & $0,37 \mathrm{~B}$ & $37 \mathrm{~A}$ & $59 \mathrm{~A}$ & $4 \mathrm{~A}$ \\
\hline Desvio-padrão & & & 0,05 & 0,04 & 4,88 & 8,40 & 0,25 & 34,47 & 33,97 & 1,22 \\
\hline \multirow[t]{9}{*}{$\mathrm{P} 4$} & & $0-10$ & 0,32 & 0,18 & 23,9 & 58,7 & 2,46 & 94 & 6 & 0 \\
\hline & & $10-20$ & 0,32 & 0,21 & 29,2 & 49,6 & 1,70 & 61 & 38 & 1 \\
\hline & & $20-30$ & 0,34 & 0,26 & 37,2 & 35,9 & 0,97 & 18 & 81 & 1 \\
\hline & & $30-40$ & 0,37 & 0,29 & 44,9 & 22,5 & 0,50 & 05 & 95 & 0 \\
\hline & Muito má & $40-50$ & 0,41 & 0,33 & 46,1 & 21,5 & 0,47 & 92 & 8 & 0 \\
\hline & & $50-60$ & 0,37 & 0,30 & 47,1 & 18,7 & 0,40 & 43 & 2 & 55 \\
\hline & & $60-70$ & 0,52 & 0,44 & 46,2 & 21,3 & 0,46 & 58 & 42 & 0 \\
\hline & & $70-80$ & 0,41 & 0,33 & 47,8 & 17,5 & 0,37 & 39 & 59 & 2 \\
\hline & & $80-90$ & 0,45 & 0,35 & 48,8 & 15,9 & 0,33 & 04 & 96 & 0 \\
\hline Média & & & $0,39 \mathrm{~B}$ & $0,30 \mathrm{~A}$ & $41,2 \mathrm{~A}$ & $29,0 \mathrm{~B}$ & $0,71 \mathrm{~B}$ & $46 \mathrm{~A}$ & $47 \mathrm{~A}$ & $7 \mathrm{~A}$ \\
\hline Desvio-padrão & & & 0,07 & 0,08 & 9,07 & 15,50 & 0,55 & 33,68 & 37,64 & 18,18 \\
\hline
\end{tabular}

${ }^{(1)}$ Embrapa (2006). ${ }^{(2)}$ Determinado pelo Analisador Elementar Flashea 1112 Series NCS (Swift, 1996). **: diferença significativa entre os perfis pelo teste $\mathrm{F}$ a $1 \%$. NS: diferença não significativa entre os perfis pelo teste F. Médias seguidas da mesma letra, nas colunas, não diferem entre si pelo teste de Scheffé a $5 \%$. 
Quadro 3. Teores de C, N, S, H, O e relações C/N, H/C e O/C obtidos em amostras de turfeiras da Serra do Espinhaço Meridional

\begin{tabular}{|c|c|c|c|c|c|c|c|c|c|}
\hline Perfil & Profundidade & C & $\mathbf{N}$ & $\mathbf{H}$ & $\mathbf{S}$ & $\mathbf{O}$ & $\mathrm{C} / \mathrm{N}$ & $\mathrm{H} / \mathrm{C}$ & $\mathrm{O} / \mathrm{C}$ \\
\hline & $\mathrm{cm}$ & & - & dag kg-1 & & & & & \\
\hline \multirow[t]{7}{*}{$\mathrm{P} 1$} & $6-66$ & 15,9 & 0,5 & 1,9 & 0,03 & 16,1 & 34,9 & 0,12 & 1,01 \\
\hline & 80-116 & 18,4 & 0,6 & 1,9 & 0,04 & 16,0 & 32,8 & 0,10 & 0,87 \\
\hline & $118-122$ & 19,3 & 0,4 & 1,6 & 0,01 & 13,3 & 35,8 & 0,08 & 0,69 \\
\hline & $124-132$ & 11,4 & 0,3 & 1,7 & 0,01 & 15,1 & 40,0 & 0,15 & 1,32 \\
\hline & $140-150$ & 8,7 & 0,2 & 1,0 & 0,02 & 9,6 & 33,6 & 0,12 & 1,10 \\
\hline & $156-166$ & 14,2 & 0,3 & 1,9 & 0,01 & 17,2 & 40,1 & 0,13 & 1,21 \\
\hline & $170-174$ & 15,9 & 0,4 & 1,8 & 0,02 & 18,5 & 39,1 & 0,11 & 1,16 \\
\hline Média & & $14,8 \mathrm{C}^{* *}$ & $0,4 \mathrm{~B} * *$ & $1,7 \mathrm{~B} * *$ & $0,02 \mathrm{C}^{* *}$ & $15,1 \mathrm{~B}^{* *}$ & $36,6 \mathrm{~A}^{* *}$ & $0,12 \mathrm{~A}$ ns & $1,10 \mathrm{~A}^{* *}$ \\
\hline Desvio-padrão & & 3,76 & 0,13 & 0,32 & 0,01 & 2,92 & 3,08 & 0,02 & 0,21 \\
\hline \multirow[t]{5}{*}{$\mathrm{P} 2$} & $0-10$ & 49,0 & 2,0 & 5,2 & 0,19 & 35,7 & 24,7 & 0,11 & 0,72 \\
\hline & $10-20$ & 49,9 & 1,9 & 4,7 & 0,17 & 36,8 & 26,4 & 0,09 & 0,73 \\
\hline & $20-30$ & 51,1 & 1,5 & 4,7 & 0,15 & 35,7 & 34,3 & 0,09 & 0,69 \\
\hline & $30-40$ & 48,2 & 1,2 & 4,7 & 0,16 & 32,3 & 40,8 & 0,10 & 0,66 \\
\hline & $40-50$ & 37,2 & 1,0 & 2,9 & 0,18 & 22,6 & 39,3 & 0,07 & 0,58 \\
\hline Média & & $47,1 \mathrm{~B}$ & $1,5 \mathrm{~A}$ & $4,4 \mathrm{~A}$ & $0,17 \mathrm{~A}$ & $32,6 \mathrm{~A}$ & $33,1 \mathrm{~A}$ & 0,09A & $0,68 \mathrm{~B}$ \\
\hline Desvio-padrão & & 5,63 & 0,43 & 0,89 & 0,02 & 5,85 & 7,32 & 0,01 & 0,06 \\
\hline \multirow[t]{9}{*}{$\mathrm{P} 4$} & $0-10$ & 21,2 & 1,5 & 3,6 & 0,05 & 28,0 & 13,8 & 0,17 & 1,32 \\
\hline & $10-20$ & 26,3 & 2,0 & 3,8 & 0,08 & 31,6 & 13,5 & 0,14 & 1,20 \\
\hline & $20-30$ & 34,2 & 2,1 & 4,1 & 0,09 & 32,9 & 16,4 & 0,12 & 0,96 \\
\hline & $30-40$ & 40,9 & 1,8 & 4,9 & 0,08 & 32,6 & 23,0 & 0,12 & 0,80 \\
\hline & $40-50$ & 41,7 & 1,8 & 4,5 & 0,09 & 34,0 & 23,1 & 0,11 & 0,82 \\
\hline & $50-60$ & 42,4 & 1,7 & 4,5 & 0,08 & 34,4 & 24,4 & 0,11 & 0,81 \\
\hline & $60-70$ & 42,0 & 1,7 & 4,4 & 0,07 & 34,0 & 24,5 & 0,11 & 0,81 \\
\hline & $70-80$ & 43,3 & 1,6 & 4,1 & 0,07 & 33,1 & 27,5 & 0,10 & 0,76 \\
\hline & $80-90$ & 44,5 & 1,2 & 3,9 & 0,03 & 29,1 & 37,9 & 0,09 & 0,65 \\
\hline Média & & $37,4 \mathrm{~A}$ & $1,7 \mathrm{~A}$ & $4,2 \mathrm{~A}$ & $0,07 \mathrm{~B}$ & $32,2 \mathrm{~A}$ & $22,7 \mathrm{~B}$ & $0,12 \mathrm{~A}$ & $0,90 \mathrm{AB}$ \\
\hline Desvio-padrão & & 8,35 & 0,27 & 0,41 & 0,02 & 2,25 & 7,62 & 0,02 & 0,22 \\
\hline
\end{tabular}

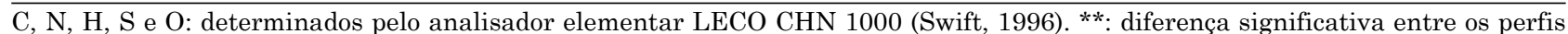
pelo teste $\mathrm{F}$ a $1 \%$. NS: diferença não significativa entre os perfis pelo teste $\mathrm{F}$. Médias seguidas da mesma letra, nas colunas, não diferem entre si pelo teste de Scheffé a $5 \%$.

A diminuição do teor de $\mathrm{N}$ em profundidade provavelmente está associada ao maior tempo de interação dos compostos orgânicos com a biota do solo, durante o qual também podem ter ocorrido reações químicas com a solução do solo (Silva et al., 2004), uma vez que a idade radiocarbônica das camadas das turfeiras P1, P2 e P4 aumenta com a profundidade (Campos et al., 2008). O aumento da relação $\mathrm{C} / \mathrm{N}$ com a profundidade evidencia maior taxa de mineralização dos compostos orgânicos mais ricos em N (Swift, 1996). Em P1, a matéria orgânica está muito decomposta (sáprica) e a relação $\mathrm{C} / \mathrm{N}$ média é a mais elevada entre os perfis estudados, apesar de não diferir estatisticamente de $\mathrm{P} 4(\mathrm{p}<0,01$ pelos testes $\mathrm{F}$ e t) (Quadro 4). Em turfeiras tropicais, relações C/N acima de 16 alteram a decomposição da matéria orgânica e, dessa forma, o teor de N (Andriesse, 1988), o que foi verificado em todos os perfis estudados, com exceção das duas primeiras camadas de P4. Para Stevenson (1994), todas as condições que favorecem a decomposição da MO (temperatura e aeração elevadas, água disponível para os microrganismos e acidez baixa) também contribuem para a redução da relação $\mathrm{C} / \mathrm{N}$.

As turfeiras $\mathrm{P} 1$ e $\mathrm{P} 4$ apresentaram valores de $\mathrm{H} / \mathrm{C}$ superiores em relação a $\mathrm{P} 2(\mathrm{p}<0,01$ pelos testes $\mathrm{F}$ e t (Quadro 3); em P1 e P2 os valores variam dentro do perfil e, em P4, eles decrescem com a profundidade. Os valores mais elevados de H/C possivelmente estão associados à redução da aromaticidade do material orgânico em ambientes de maior oxidação do solo, ou seja, onde a drenagem é melhor (Valladares, 2003). Como P2 e P4 (com exceção das duas primeiras camadas) são ambientes de maior redução, mal drenados, isso pode favorecer a maior quantidade de estruturas aromáticas, em razão da menor taxa de decomposição da MO propiciada pelas condições de anaerobiose (Ferreira, 2008).

Os elevados valores de $\mathrm{O} / \mathrm{C}$ encontrados em $\mathrm{P} 1 \mathrm{em}$ relação a P2 e $\mathrm{P} 4(\mathrm{p}<0,01$ pelo teste $\mathrm{F}$ e p $<0,05$ pelo teste de Scheffé) (Quadro 3) indicam que as reações de oxidação são intensas e as de descarboxilação e demetilação são inferiores (Canellas \& Santos, 2005). 
A relação $\mathrm{O} / \mathrm{C}$ oscila em $\mathrm{P} 1$ e decresce em profundidade em P2 e P4. O perfil P1 é moderadamente drenado e, por isso, apresenta menor potencial redox do que os demais perfis estudados, o que favorece a formação de compostos menos aromatizados e com maiores teores de grupos carboxílicos (Valladares, 2003). Os valores mais elevados da relação $\mathrm{O} / \mathrm{C}$ em $\mathrm{P} 1$ também estão relacionados aos seus teores de ácidos fúlvicos, muito superiores àqueles encontrados em P2 e P3 $(\mathrm{p}<0,01$ pelo teste $\mathrm{F}$ e $\mathrm{p}<0,05$ pelo teste de Scheffé) (Quadro 4), e estes ácidos possuem teores de $\mathrm{O}$ mais elevados do que os ácidos húmicos (Breemen \& Buurman, 2002).

De acordo com Andriesse (1988) e Galvão \& Vahl (1996), a composição química das turfeiras é influenciada diretamente pela porção mineral, pela natureza do material orgânico, pelo grau de decomposição da matéria orgânica e pela composição química da água de formação, o que contribui para que ocorra ampla variação na composição mineral desses solos entre si e entre os horizontes de um mesmo solo. Essas constatações são corroboradas no presente trabalho, uma vez que, de acordo com o Sistema Brasileiro de Classificação de Solos (Embrapa, 2006), P1 corresponde a um Organossolo Háplico sáprico térrico, com acentuada decomposição da matéria orgânica e significativos teores de areia (Quadro 2); P2 corresponde a um Organossolo Háplico Fíbrico típico, apresentando matéria orgânica em estádio de decomposição menos avançado; e P4 corresponde a um Organossolo Háplico Hêmico típico, com matéria orgânica em estádio intermediário de decomposição. A turfeira $\mathrm{P} 1$ possui drenagem moderada e as turfeiras P2 e P4 são muito mal drenadas.

\section{Fracionamento químico da matéria orgânica}

Os teores de Corg como substâncias húmicas nos três perfis estudados são: $\mathrm{P} 1$ - ácido fúlvico $(\mathrm{AF})>$ ácido húmico $(\mathrm{AH})>>$ humina $(\mathrm{H})$; e $\mathrm{P} 2$ e $\mathrm{P} 4-\mathrm{H}>>$ $\mathrm{AH}>\mathrm{AF}$ (Quadro 4). Essas substâncias húmicas apresentam características químicas, físicas e morfológicas distintas, e a distribuição dessas frações pode indicar a qualidade da matéria orgânica do solo (Lima, 2004).

A evolução do húmus pode ser modificada pelo hidromorfismo. As turfeiras P2 e P4 são ambientes muito mal drenados; portanto, a via de herança (evolução direta dos compostos insolúveis lignificados da matéria orgânica pouco transformada) é o processo de humificação predominante nesses perfis, pois as outras vias de humificação, como a de neossíntese microbiana, que consiste na humificação das moléculas simples por meio da síntese microbiana, e a de insolubilização, ou humificação dos compostos fenólicos solúveis, necessitam de elevada pressão de $\mathrm{O}_{2}$ para manter a atividade da microbiota do solo (Dablin, 1981).

Por meio da via de herança nos perfis mal drenados há acúmulo de humina: em P2 foram determinados os mais elevados valores médios de humina

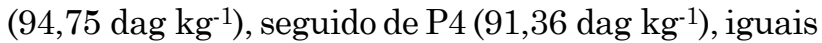
estatisticamente (Quadro 4), e em ambos a amplitude foi baixa. Para Breemen \& Buurman (2002), a humina representa a fração mais heterogênea da matéria orgânica do solo, formada por compostos organominerais, carvão, componentes apolares e restos vegetais não decompostos. Dessa forma, pode-se inferir que a matéria orgânica de $\mathrm{P} 1$ - que possui teor médio de humina de 6,00 dag $\mathrm{kg}^{-1}$ - encontra-se em um estádio de decomposição bem mais avançado que em P2 e P4.

Os elevados teores de AF em P1 (Quadro 4), substâncias mais ou menos polimerizadas, podem ser devido à moderada drenagem deste perfil, que favoreceu a polimerização e policondensação de precursores fenólicos solúveis, que são mais estáveis ao longo do tempo (Duchaufour, 1977; Conceição et al., 1999). Valladares (2003), estudando três perfis de turfeiras de Nova Friburgo-RJ, obteve, em camadas com teores de carbono orgânico e teores de fibras esfregadas relativamente baixos, valores maiores de ácido fúlvico do que de humina, conforme foi constatado em P1.

Os AH são compostos estáveis, ou seja, recalcitrantes (Stevenson, 1994). O perfil P1 foi o que apresentou o maior teor médio de $\mathrm{AH}$ e o maior teor absoluto entre os perfis estudados, de 31,26 dag kg-1 na camada de 30 a $40 \mathrm{~cm}$ de profundidade. Os perfis $\mathrm{P} 2$ e $\mathrm{P} 4$ apresentaram teores médios de $\mathrm{AH}$ abaixo de 5,81 dag $\mathrm{kg}^{-1}$ e iguais estatisticamente (Quadro 4), evidenciando que a matéria orgânica destes perfis está em estádio de decomposição menos avançado em relação a P1. Como nessa turfeira a drenagem é melhor do que a dos demais perfis, ocorre maior mineralização da MO e maior formação de substâncias húmicas (Senesi \& Loffredo, 1999). De acordo com Zech et al. (1997), a intensificação do processo de humificação leva ao enriquecimento das substâncias humicas em estruturas aromáticas, condensadas e recalcitrantes, o que corrobora a classificação de P1 como Organossolo Háplico sáprico.

A razão AH/AF foi usada por Kononova (1982) como indicador da qualidade das substâncias húmicas, pois expressa o grau de evolução do processo de humificação da matéria orgânica. Em solos tropicais, normalmente, essa razão é inferior a 1 devido à menor intensidade do processo de humificação, ou seja, condensação e síntese, atribuídas à intensa mineralização dos resíduos, às restrições edáficas e ao baixo conteúdo de bases trocáveis, restringindo a atividade biológica nos solos intensamente intemperizados (Cerri \& Volkoff, 1988; Breemen \& Buurman, 2002; Canellas et al., 2002). Em P1 e nas profundidades de 0 a $20 \mathrm{~cm}$ de $\mathrm{P} 4$, os valores da relação $\mathrm{AH} / \mathrm{AF}$ foram menores que 1. Esses baixos valores estariam relacionados ao seus elevados teores de $\mathrm{AF}$ e da FM (Quadro 2).

A relação $\mathrm{EA} / \mathrm{H}$, em que a EA é a soma das frações $\mathrm{AH}$ e AF e H é a humina, fornece informações sobre a 
Quadro 4. Carbono orgânico como ácido húmico (AH), ácido fúlvico (AF), humina (H), relação AH/AF e relação $\mathrm{EA} / \mathrm{H}$ nos perfis e teores de $\mathrm{C}, \mathrm{N}, \mathrm{S}$, relação $\mathrm{C} / \mathrm{N}$ e teor de cinzas da fração ácido húmico (AH) obtidos em perfis de turfeiras da Serra do Espinhaço Meridional

\begin{tabular}{|c|c|c|c|c|c|c|c|c|c|c|c|}
\hline \multirow{2}{*}{ Perfil } & \multirow{2}{*}{ Prof. } & \multicolumn{3}{|c|}{ C orgânico como } & \multirow{2}{*}{$\mathbf{A H} / \mathbf{A F}$} & \multirow{2}{*}{ EA/H } & \multicolumn{5}{|c|}{ AH } \\
\hline & & $\mathbf{A H}$ & $\mathbf{A F}$ & $\mathbf{H}$ & & & $\mathbf{C}$ & $\mathbf{N}$ & $\mathbf{S}$ & $\mathrm{C} / \mathrm{N}$ & Cinzas \\
\hline \multirow{8}{*}{$\mathrm{P} 1$} & $\mathrm{~cm}$ & \multicolumn{3}{|c|}{$\mathrm{dag} \mathrm{kg}^{-1}$} & & & \multicolumn{3}{|c|}{$\mathrm{dag} \mathrm{kg}^{-1} \longleftarrow$} & & $\%$ \\
\hline & $6-66$ & 31,18 & 64,21 & 4,61 & 0,49 & 14,90 & 62,67 & 1,59 & 0,04 & 39,30 & 19,74 \\
\hline & $80-116$ & 29,27 & 64,44 & 6,29 & 0,45 & 22,42 & 58,12 & 1,41 & 0,04 & 41,17 & 9,32 \\
\hline & $118-122$ & 21,27 & 74,46 & 4,27 & 0,29 & 13,35 & 53,89 & 0,99 & 0,00 & 54,40 & 15,20 \\
\hline & $124-132$ & 29,61 & 63,43 & 6,97 & 0,47 & 22,47 & 71,51 & 1,36 & 0,00 & 52,52 & 18,47 \\
\hline & $140-150$ & 27,92 & 67,82 & 4,26 & 0,41 & 8,67 & 59,22 & 0,99 & 0,00 & 59,78 & 7,12 \\
\hline & $156-166$ & 31,26 & 58,40 & 10,34 & 0,54 & 18,09 & 51,38 & 1,14 & 0,00 & 45,00 & 5,42 \\
\hline & $170-174$ & 31,14 & 63,63 & 5,24 & 0,49 & 15,67 & 74,46 & 1,33 & 0,00 & 55,97 & 6,80 \\
\hline Média & & $28,81 \mathrm{~A}^{* *}$ & $65,20 \mathrm{~A}^{* *}$ & $6,00 \mathrm{C}^{* *}$ & $0,45 \mathrm{C}^{* *}$ & $17,23 \mathrm{~A}^{* *}$ & $61,61 \mathrm{~A}^{\mathrm{ns}}$ & $1,26 \mathrm{~B}^{* *}$ & $0,01 \mathrm{~A}^{\mathrm{ns}}$ & $49,73 \mathrm{~A}^{* *}$ & $11,72 \mathrm{~A}^{\mathrm{ns}}$ \\
\hline \multicolumn{2}{|c|}{ Desvio-padrão } & 3,55 & 4,93 & 2,18 & 0,08 & 4,96 & 8,63 & 0,23 & 0,02 & 7,89 & 5,96 \\
\hline \multirow[t]{5}{*}{$\mathrm{P} 2$} & $0-10$ & 2,35 & 1,39 & 96,26 & 1,69 & 0,04 & 51,83 & 2,57 & 0,10 & 20,20 & 4,49 \\
\hline & $10-20$ & 5,07 & 0,93 & 94,00 & 5,45 & 0,06 & 52,43 & 1,79 & 0,06 & 29,27 & 16,27 \\
\hline & $20-30$ & 3,99 & 0,79 & 95,21 & 5,05 & 0,05 & 51,88 & 1,82 & 0,03 & 28,50 & 8,24 \\
\hline & $30-40$ & 4,64 & 0,59 & 94,77 & 7,86 & 0,06 & 52,30 & 1,59 & 0,04 & 32,89 & 4,40 \\
\hline & $40-50$ & 5,08 & 1,40 & 93,52 & 3,63 & 0,07 & 67,44 & 1,97 & 0,04 & 34,23 & 17,26 \\
\hline \multicolumn{2}{|l|}{ Média } & $4,23 \mathrm{~B}$ & $1,02 \mathrm{~B}$ & $94,75 \mathrm{~A}$ & $4,74 \mathrm{~A}$ & $0,06 \mathrm{~B}$ & $55,18 \mathrm{~A}$ & $1,95 \mathrm{AB}$ & $0,05 \mathrm{~A}$ & $29,02 B$ & $10,13 \mathrm{~A}$ \\
\hline \multicolumn{2}{|c|}{ Desvio-padrão } & 1,14 & 0,36 & 1,07 & 2,28 & 0,01 & 6,86 & 0,37 & 0,03 & 5,48 & 6,26 \\
\hline \multirow[t]{9}{*}{$\mathrm{P} 4$} & $0-10$ & 3,90 & 4,59 & 91,52 & 0,85 & 0,09 & 54,16 & 4,14 & 0,07 & 13,07 & 10,46 \\
\hline & $10-20$ & 3,13 & 5,01 & 91,86 & 0,62 & 0,09 & 56,02 & 4,09 & 0,10 & 13,69 & 11,27 \\
\hline & $20-30$ & 6,06 & 2,14 & 91,80 & 2,83 & 0,09 & 50,30 & 2,40 & 0,00 & 20,99 & 7,35 \\
\hline & $30-40$ & 9,71 & 2,74 & 87,54 & 3,54 & 0,14 & 57,82 & 2,00 & 0,00 & 28,95 & 14,39 \\
\hline & $40-50$ & 7,81 & 2,93 & 89,26 & 2,67 & 0,12 & 50,76 & 1,79 & 0,00 & 28,36 & 11,15 \\
\hline & $50-60$ & 5,12 & 2,65 & 92,23 & 1,93 & 0,08 & 59,89 & 1,96 & 0,00 & 30,51 & 10,83 \\
\hline & $60-70$ & 3,57 & 1,69 & 94,75 & 2,11 & 0,06 & 54,01 & 1,83 & 0,00 & 29,47 & 7,23 \\
\hline & $70-80$ & 5,37 & 2,20 & 92,44 & 2,44 & 0,08 & 65,35 & 1,98 & 0,00 & 32,97 & 20,27 \\
\hline & $80-90$ & 7,59 & 1,56 & 90,85 & 4,87 & 0,10 & 52,35 & 1,11 & 0,00 & 47,13 & 15,38 \\
\hline \multicolumn{2}{|l|}{ Média } & $5,81 \mathrm{~B}$ & $2,83 \mathrm{~B}$ & $91,36 \mathrm{~B}$ & $2,43 \mathrm{~B}$ & $0,10 \mathrm{~B}$ & $55,63 \mathrm{~A}$ & $2,37 \mathrm{~A}$ & $0,02 \mathrm{~A}$ & $27,24 \mathrm{~B}$ & $12,04 \mathrm{~A}$ \\
\hline \multicolumn{2}{|c|}{ Desvio-padrão } & 2,21 & 1,21 & 2,04 & 1,30 & 0,02 & 4,81 & 1,05 & 0,04 & 10,44 & 4,11 \\
\hline
\end{tabular}

$\mathrm{EA}=\mathrm{AH}+\mathrm{AF} . \mathrm{AF}, \mathrm{AH}, \mathrm{H}, \mathrm{C}, \mathrm{N}, \mathrm{S}$ e cinzas (Swift, 1996). **: diferença significativa entre os perfis pelo teste F a $1 \%$. NS. diferença não significativa entre os perfis pelo teste F. Médias seguidas da mesma letra, nas colunas, não diferem entre si pelo teste de Scheffé a $5 \%$.

gênese do solo, identificando zonas de movimentação e acúmulo de carbono (Benites, 1998). Em P1, os valores da relação $\mathrm{EA} / \mathrm{H}$ foram muito mais elevados do que em $\mathrm{P} 4$ e P2 e as diferenças foram significativas ( $\mathrm{p}<0,01$ pelo teste $\mathrm{F}$ e $\mathrm{p}<0,05$ pelo teste de Scheffé) (Quadro 4). Os valores de EA/H não variaram muito dentro dos perfis, indicando que nesses solos vários fatores podem ter influenciado a proporção de AF e $\mathrm{AH}$, incluindo ambiente de formação e clima. Os elevados valores de P1 coincidem com os elevados valores da FM no mesmo perfil (Quadro 2), o que evidencia a grande interação dos AH com a matriz mineral do solo. A turfeira P2, que possui uma única camada assentada sobre a rocha, em ambiente de relevo montanhoso, apresentou baixa relação EA/H, possivelmente devido à exportação para o lençol freático das frações húmicas mais solúveis e à manutenção das frações insolúveis, ao clima mais frio $(1.800 \mathrm{~m}$ de altitude) e à má drenagem.
De acordo com Sposito (1989), a fração AH possui em média 56 dag kg-1 de Corg, 0,8 e 3,2 dag kg-1 de $\mathrm{S}$ e N, respectivamente. Os teores médios e absolutos de Corg nos três perfis estão próximos desse valor (Quadro 4). O teor de S é muito baixo em todos os perfis estudados, apresentando valores maiores nas primeiras camadas, e não foi detectado em muitas camadas de P1 e P4, provavelmente por apresentarem materiais minerais com teores distintos de S. O teor de $\mathrm{N}$ mostrou pouca oscilação em P1 e P2, porém em $\mathrm{P} 4$ ele decresceu com a profundidade. A relação $\mathrm{C} / \mathrm{N}$ dos AH aumenta em profundidade nos três perfis e é muito mais elevada em $\mathrm{P} 1$ ( $p<0,01$ pelo teste $\mathrm{F}$ e $\mathrm{p}<0,05$ pelo teste de Scheffé) (Quadro 4) e em profundidade nos três perfis estudados. Silva et al. (2004) também observaram diminuição do teor de $\mathrm{Ne}$ aumento da relação $\mathrm{C} / \mathrm{N}$ com a profundidade de ácidos húmicos extraídos de amostras de Latossolos húmicos, relacionando essa constatação com o aumento do grau 
de humificação (maior teor de semiquinona) e com a elevação da idade radiocarbônica das camadas. Martin Neto et al. (1994) relatam que, quanto maior o grau de humificação, menor a relação $\mathrm{C} / \mathrm{N}$ dos $\mathrm{AH}$ extraídos de Chernossolos. Contudo, deve-se considerar que tanto Silva et al. (2004) como Martin Neto et al. (1994) estudaram substâncias húmicas em solos minerais, uma vez que os primeiros trabalharam com solos intensamente intemperizados (Latossolos) e os últimos com solos menos intemperizados (Chernossolos). Estudos espectrométricos devem ser realizados em Organossolos, para verificar as variações da relação $\mathrm{C} / \mathrm{N}$ em função da quantificação dos teores de semiquinona contidos nos AH extraídos desses solos.

\section{CONCLUSÕES}

1. A matéria orgânica de perfis de turfeiras da SdEM apresentou marcantes diferenças em relação à sua composição química e à quantidade de substâncias húmicas e à composição química dos ácidos húmicos.

2. A variação nas condições de drenagem foi preponderante para a diferenciação qualiquantitativa da matéria orgânica das turfeiras: P1, onde as condições de drenagem são moderadas, apresentou maiores relações $\mathrm{C} / \mathrm{N}$ e $\mathrm{O} / \mathrm{C}$ médias, predomínio de ácidos fúlvicos na fração humificada e ácidos húmicos com a mais elevada relação $\mathrm{C} / \mathrm{N}$ média; já $\mathrm{P} 2$ e $\mathrm{P} 4$, onde as condições de drenagem são muito más, apresentaram mais baixas relações $\mathrm{C} / \mathrm{N}$ e $\mathrm{O} / \mathrm{C}$ médias, amplo predomínio de humina na fração humificada e ácidos húmicos com mais baixa relação $\mathrm{C} / \mathrm{N}$ média.

\section{AGRADECIMENTOS}

À Fundação de Amparo à Pesquisa do Estado de Minas Gerais - FAPEMIG, pelo apoio financeiro para execução de parte deste trabalho, ao IEF/MG (Parques Estaduais do Biribiri e do Pico do Itambé) e à COPASA (APA Pau-de-Fruta).

\section{LITERATURA CITADA}

ANDRIESSE, J.P. Nature and management of tropical peat soils. Rome, FAO, 1988. (FAO Soils Bulletin, 59)

BENITES, V.M. Caracterização química e espectroscópica da matéria orgânica e suas relações com a gênese de solos da Serra do Brigadeiro, Zona da Mata Mineira. Viçosa, MG, Universidade Federal de Viçosa, 1998. 125p. (Tese de Mestrado)
BLOMBÄCK, K.; ECKERSTEN, H.; LEWAN, E. \& ARONSSON, H. Simulations of soil carbon and nitrogen dynamics during seven years in a catch crop experiment. Agric. Syst., 76:95-114, 2003.

BREEMEN, N. \& BUURMAN, P. Soil formation. 2.ed. Dordrecht, Kluwer Academic Publishers, 2002. 404p.

CAMARGO, F.A.O.; SANTOS, G.A. \& GUERRA, J.G.M. Macromoléculas e substâncias húmicas. In: SANTOS, G.A. \& CAMARGO, F.A.O., eds. Fundamentos da matéria orgânica do solo: Ecossistemas tropicais e subtropicais. Porto Alegre, Gênesis, 1999. p.27-39.

CAMPOS, J.R.R.; SILVA, A.C.; SILVA, D.V.; VASCONCELOS, L.L.; ROMÃO, R.V.; BISPO, F.H.A. \& HORAK, I. Idades radiocarbônicas e acumulação antrópica de metais pesados em turfeiras da Apa Pau-De-Fruta, Diamantina - MG. In: FERTBIO 2008, Londrina, 2008. CD ROM.

CANELLAS, L.P.; VELOSSO, A.C.X.; RUMJANEK, V.M.; GURIDI, F.; OLIVARES, F.L.; SANTOS, G.A. \& BRAZFILHO, R. Distribution of the humified fractions and characteristics of the humic acids of an Ultisol under cultivation of Eucalyptus and sugar cane. Terra, 20:371381,2002

CANELLAS, L.P. \& SANTOS, G.A. Humosfera: Tratado preliminar sobre a química das substâncias húmicas. Campos dos Goytacazes, CCTA / UENF, 2005. 309p.

CERRI, C.C. \& VOLKOFF, B. Matéria orgânica de três solos dos campos inundáveis da Ilha de Marajó/PA. R. Bras. Ci. Solo, 12:93-100, 1988.

CONCEIÇÃO, M.; FREIXO, A.A.; ARAÚJO, W.S.; CUNHA, T.J.F.; MARTIN NETO, L. \& SAAB, S.C. Caracterização das substâncias em solos orgânicos do estado do Rio de Janeiro, sob diversas atividades agrícolas. Rio de Janeiro, 1999c. 6p. (Série EMBRAPA - Pesquisa em Andamento)

DABLIN, B. Les matières organiques dans les sols tropicaux normalement drainès. Cah. ORSTOM. Sér. Pédol., 18:197$215,1981$.

DUCHAUfOUR, P. Pédologie: Pédogenèse et classification. Paris, Masson, 1977. 477p.

EMPRESA BRASILEIRA DE PESQUISA AGROPECUÁRIA EMBRAPA. Centro Nacional de Pesquisa de Solos. Sistema brasileiro de classificação de solos. Brasília, Embrapa Produção de Informação; Rio de Janeiro, Embrapa Solos, 2006. 312p.

EMPRESA BRASILEIRA DE PESQUISA AGROPECUÁRIA EMBRAPA. Centro Nacional de Pesquisa de Solos. Sistema brasileiro de classificação de solos. Brasília, Embrapa Produção da Informação; Rio de Janeiro, Embrapa Solos, 1999. 412p.

EMPRESA BRASILEIRA DE PESQUISA AGROPECUÁRIA EMBRAPA. Centro Nacional de Pesquisa de Solos. Manual de métodos de análises de solos. Campinas, 1997. 212 p.

FERREIRA, F.P. Caracterização de substâncias húmicas extraídas do solo do manguezal de Pai Matos (Cananéia, SP) e de marismas da Espanha (Galícia e Valência). Piracicaba, ESALQ/USP, 2008. 125p. (Tese de Doutorado) 
GALVÃO, F.A.D. \& VAHL, L.C. Propriedades químicas dos solos orgânicos do litoral do Rio Grande do Sul e Santa Catarina. R. Bras. Agroci., 2:131-135, 1996.

HORAK, I.; SILVA A.C.; FERREIRA C.A.; RODRÍGUEZ RACEDO, J.; MARTÍNEZ CORTIZAS, A.; SILVA, E.B. \& GRAZZIOTTI, P.H. Turfeiras da Serra do Espinhaço Meridional - MG: I - Caracterização morfológica, física, química e microbiológica. In: CONGRESSO BRASILEIRO DE CIÊNCIA DO SOLO, 31., Gramado, 2007.Anais. Gramado, Sociedade Brasileira de Ciência do Solo, 2007. p.36.

KONONOVA, M.M. Matéria orgânica del suelo; su natureza, propriedades y métodos de investigation. Barcelona, Oikos - Tau, 1982. 365p.

LIMA, A.M.N. Estoque de carbono e frações da matéria orgânica do solo sob povoamento de eucalipto no Vale do Rio Doce - MG. Viçosa, MG, Universidade Federal de Viçosa, 2004. 109p. (Tese de Doutorado)

MARTIN NETO, L.; ANDRIULLI, A.E. \& TRAGHETTA, D.G. Effects of cultivation on ESR spectra of organic matter from soil size fractions of a Mollisol. Soil Sci., 156:365376, 1994.

NELSON, D.W. \& SOMMERS, L.E. Total carbon, organic carbon and organic matter. In: SPARKS, D.L.; PAGE, A.L.; HELMKE, P.A.; LOEPPERT, R.H.; SOLTANPOUR, P.N.; TABATABAI, M.A.; JOHNSTON, C.T. \& SUMMER, M.E., eds. Methods of soil analysis. Chemical methods. Madison, Soil Science Society of America/American Society of Agronomy, 1996. Part 3. p.961-1009. (Book Series, 5)

PRIMAVESI, A. Manejo Ecológico do Solo. São Paulo, Nobel, 1991. 552p.

SCHNITZER, M. Soil organic matter - The next 75 years. Soil Sci., 151: 41-58, 1991.

SENESI, N. \& LOFFREDO, E. The chemistry of soil organic matter. In: SPARKS, D.L. ed. Soil physical chemistry. Boca Raton, CRC Press, 1999. p.242-370.

SILVA, A.C.; PEDREIRA, L.C.V.S.F. \& ALMEIDA ABREU, P.A. Serra do Espinhaço Meridional: Paisagens e ambientes. Belo Horizonte, O Lutador, 2005. 272p.
SILVA, A.C.; VIDAL TORRADO, P.; PÉREZ, M.G.; MARTIN NETO, L. \& VASQUEZ, F.M. Relações entre matéria orgânica do solo e declividade de vertentes em Topossequência de Latossolos do sul de Minas Gerais. R. Bras. Ci. Solo, 31:1059-1068, 2004.

SILVA, A.C.; HORÁK, I.; VIDAL-TORRADO, P.; MARTINEZ CORTIZAS, A.; RODRIGUES RACEDO, J.; GRAZZIOTTI, P.H.; SILVA, E.B. \& FERREIRA, C.A. Turfeiras da Serra do Espinhaço Meridional - MG. I - Caracterização e classificação. R. Bras. Ci. Solo, 33:1385-1398.

SPOSITO, G. The chemistry of soils. New York, Oxford University Press, 1989. 277p.

STANEK, W. \& SILC, T. Comparisons of four methods for determination of degree of peat humification (decomposition) with emphasis on the von Post method. Canad. J. Soil Sci., 57:109-117, 1977.

STEVENSON, F.J. Humus chemistry: Genesis, composition, reactions. 2.ed. New York, Willey, 1994. 496p.

SWIFT, R.S. Organic matter characterization. In: SPARKS, D.L.; PAGE, A.L.; HELMKE, P.A.; LOEPPERT, R.H.; SOLTANPOUR, P.N.; TABATABAI, M.A.; JOHNSTON, C.T. \& SUMMER, M.E., eds. Methods of soil analysis. Chemical methods. Madison, Soil Science Society of America/American Society of Agronomy, 1996. Part 3. p.1011-1069. (Book Series, 5)

VALLADARES, G.S. Caracterização de Organossolos, auxílio à sua classificação. Seropédica, Universidade Federal Rural do Rio de Janeiro, 2003. 115p. (Tese de Doutorado)

VALLADARES G.S.; GOMES, E.G.; MELLO, J.C.C.B.S.; PEREIRA, M.G.; ANJOS, L.H.C.; EBELING, A.G. \& BENITES, V.M. Análise dos componentes principais e métodos multicritério ordinais no estudo de Organossolos e solos afins. R. Bras. Ci. Solo., 32:285-296, 2008.

WALKLEY \& BLACK, I.A. An examination of the Degtjareff method for determining soil organic matter and a proposed modification of the cromic acid titration method. Soil Sci., 37:29-38, 1934.

ZECH, W.; SENESI, N.; GUGGENBERGER, G.; KAISER, K.; LEHMANN, K.; MILTNER, A.; MIANO, T.M. \& SCHROTH, G. Factors controlling humification and mineralizing of soil organic matter in the tropics. Geoderma, 79:117-161, 1997. 